\title{
Recent advancements of total aortic arch replacement
}

\author{
Kenji Okada, MD, PhD, Atsushi Omura, MD, Hiroya Kano, Toshihito Sakamoto, MD, Akiko Tanaka, MD, \\ Takeshi Inoue, MD, and Yutaka Okita, MD, PhD
}

Objective: Recent advancements in total aortic arch replacement achieved by our approach were presented.

\begin{abstract}
Methods: From January 2002 to December 2010, 321 consecutive patients (mean age $69.8 \pm 13.3$ years) underwent total arch replacement through a median sternotomy at our institute. Aortic dissection was present in $94(28.3 \%)$ patients and shaggy aorta in $36(11.2 \%)$, with emergency/urgent surgery required in 106 $(33.0 \%)$. Our current approach included the following: (1) meticulous selection of arterial cannulation site and type of arterial cannula; (2) antegrade selective cerebral perfusion; (3) maintenance of minimal tympanic temperature between $20^{\circ} \mathrm{C}$ and $23^{\circ} \mathrm{C}$; (4) early rewarming just after distal anastomosis; (5) after 2004, bolus injection of $100 \mathrm{mg}$ of sivelestat sodium hydrate into the pump circuit at the initiation of cardiopulmonary bypass; (6) after 2006, maintaining fluid balance below $1000 \mathrm{~mL}$ during cardiopulmonary bypass.
\end{abstract}

Results: Overall hospital mortality was 4.4\% (14/321) and was 1.9\% (4/215) in elective cases. Permanent neurologic deficit occurred in $4.4 \%$ (14/321) of patients and in $2.8 \%(6 / 215)$ of elective cases. Prolonged ventilation was necessary in $53(16.5 \%)$, with a significant reduction after $2006(22.8 \%$ vs $12.6 \% ; P=.02)$. Multivariate analysis demonstrated that risk factors for hospital mortality were octogenarian (odds ratio, 4.32; $P=.03$ ), brain malperfusion (odds ratio, 21.2; $P=.001$ ) and cardiopulmonary bypass time (odds ratio, $1.01 ; P=.04$ ). Survival at 3 and 5 years after surgery was $82.4 \% \pm 2.5 \%$ and $78.5 \% \pm 3.1 \%$, respectively.

Conclusions: Our current approach for total aortic arch replacement was associated with low hospital mortality and morbidities and with favorable long-term outcome. (J Thorac Cardiovasc Surg 2012;144:139-45)

Surgical techniques, perioperative care, and sealing grafts in the field of aortic arch surgery have improved dramatically over the past decade. Consequently, recent literature has described improved outcomes in hospital mortality, with rates of $5 \%$ or lower cited, ${ }^{1-3}$ whereas in the past figures in the range of $10 \%$ were reported. It becomes imperative to devise not only surgical techniques, but also preoperative accurate imaging for aortic disease, and to monitor brain perfusion, fluid balance during cardiopulmonary bypass (CPB), and pharmacologic interventions for pulmonary protection, which may lead to further improvement in short- and long-tem outcomes in the treatment of aortic arch disease.

The purpose of this retrospective study is to describe our surgical approach for total aortic arch replacement (TAR) and the satisfactory outcomes experienced at our institute.

\section{PATIENTS AND METHODS}

This study was approved by our institutional review board, and the need for individual consent was waived.

\footnotetext{
From the Division of Cardiovascular Surgery, Department of Surgery, Kobe University Graduate School of Medicine, Kobe, Japan.

Disclosures: Authors have nothing to disclose with regard to commercial support.

Received for publication May 18, 2011; revisions received July 6, 2011; accepted for publication Aug 25, 2011; available ahead of print Sept 28, 2011.

Address for reprints: Yutaka Okita, MD, PhD, Department of Surgery, Divisions of Cardiovascular Surgery, Kobe University Graduate School of Medicine, 7-5-2,

Kusunoki-Cho, Chuo-Ku, Kobe, Hyogo, 650-0017, Japan (E-mail: yokita@med. kobe-u.ac.jp).

0022-5223/\$36.00

Copyright (c) 2012 by The American Association for Thoracic Surgery

doi:10.1016/j.jtcvs.2011.08.039
}

\section{Patient Profiles (Table 1)}

From January 2002 to December 2010, 321 consecutive patients with a mean age of $69.8 \pm 13.3$ years who underwent TAR through a median sternotomy were retrospectively investigated. There were 66 (20.6\%) octogenarians in the series. The type of aortic disease was aortic dissection in 94 $(28.3 \%)$ including acute type A dissection in $61(19.0 \%)$ and Marfan syndrome in $11(3.4 \%)$. "Shaggy aorta" in the aortic arch was observed in 36 $(11.2 \%)$. "Shaggy aorta" was defined as very extensive atheromatous disease with diffuse ulcers associated with soft, loosely held debris and a paucity of actual thrombus; the term was advocated by Hollier and associates. ${ }^{4}$ Accordingly, when fragile and spiculated atheroma more than $5 \mathrm{~mm}$ in thickness was confirmed by both computed tomography and visual inspection in the aortic arch except the aneurysm itself, the arch pathologic condition was defined as shaggy aorta in the current study. Surgery was performed on an emergency/urgent basis in $106(33.0 \%)$ patients. Other conditions included a history of cerebral infarction in $32(10.0 \%)$ patients, $72(22.4 \%)$ with coronary artery disease, $23(7.2 \%)$ with chronic obstructive pulmonary disease, and $25(7.8 \%)$ with chronic kidney disease (creatinine $\geq 2.0 \mathrm{mg} / \mathrm{dL}$ ).

\section{Current Surgical Approach}

Our current approach since 2002 has been (1) meticulous selection of arterial cannulation site and type of arterial cannula; (2) antegrade selective cerebral perfusion (SCP) for cerebral protection; (3) whole body hypothermia with minimal tympanic temperatures between $20^{\circ} \mathrm{C}$ and $23^{\circ} \mathrm{C}$, and minimal rectal temperatures below $30^{\circ} \mathrm{C}$; (4) early rewarming after distal anastomosis with antegrade SCP flow adjustment while monitoring brain oxygenation by near-infrared spectroscopy (NIRS); (5) after 2004, bolus injection of $100 \mathrm{mg}$ of sivelestat sodium hydrate (ONO-5046) into the pump circuit at the initiation of $\mathrm{CPB}^{5}$; and (6) after 2006, maintaining strict fluid balance below $1000 \mathrm{~mL}$ by the extracorporeal ultrafiltration method during $\mathrm{CPB}$, with the expectation of more rapid pulmonary functional recovery. This overall approach has been applied for all cases since 2006.

Patients were placed in the supine position and the diodes of NIRS were attached on the foreheads bilaterally. For NIRS we used INVOS 5100C (Somanetics, Troy, Mich), which provides continuous regional cerebral 

Abbreviations and Acronyms
$\mathrm{CA}=$ circulatory arrest
$\mathrm{CPB}=$ cardiopulmonary bypass
NIRS $=$ near-infrared spectroscopy
$\mathrm{OR}=$ odds ratio
PND $=$ permanent neurologic deficit
$\mathrm{rSO}_{2}=$ regional cerebral oxygen saturation
SCP $=$ selective cerebral perfusion
$\mathrm{TAR}=$ total aortic arch replacement
TND $=$ transient neurologic deficit

oxygen saturation $\left(\mathrm{rSO}_{2}\right)$. The $\mathrm{rSO}_{2}$ readings are expressed as an index, measuring differences from an unknown baseline.

Figure 1, $A$ to $H$, shows a diagrammatic representation of the TAR procedure. CPB was established with bicaval drainage and the ascending aortic perfusion in the majority of cases $(n=244,76.0 \%$, Table 1 , Figure 1 , $B)$. The left side of the ventricle was vented through the right upper pulmonary vein. Femoral artery cannulation was applied $(\mathrm{n}=54,16.8 \%$, Table 1), particularly in patients with aortic dissection. The selection of aortic cannulas depended on the aortic disease, with the site being determined by the findings of a preoperative computed tomographic and intraoperative epiaortic echographic scan. If the ascending aorta/aortic arch was highly diseased, a 24F Dispersion arterial cannula (Duraflo II; Edwards Lifesciences LLC, Irvine, Calif) was inserted near the aortic root with perfusion toward the aortic valve $(\mathrm{n}=46,14.3 \%)$. All patients received $100 \mathrm{mg}$ of betamethasone sodium phosphate, and, after 2004, $100 \mathrm{mg}$ of sivelestat sodium hydrate was added to the pump circuit at the initiation of CPB. After the tympanic temperature had dropped to $20^{\circ} \mathrm{C}$ to $23^{\circ} \mathrm{C}$ with rectal temperature below $30^{\circ} \mathrm{C}$, the aortic arch aneurysm was opened (Figure 1,C) and antegrade SCP initiated. A $14 \mathrm{~F}$ or $16 \mathrm{~F}$ balloon-tipped cannula was inserted from inside the aorta into the brachiocephalic artery, and $12 \mathrm{~F}$ cannulas were positioned in the left common carotid and left subclavian arteries. Avoiding cerebral embolism was particularly important in SCP cannulation. If the ostia of the arch vessels were severely atherosclerotic, arteriotomy of the arch vessels was extended from the diseased ostium to a relatively clear distal part and then cannulas were placed in position under direct vision. Antegrade SCP flow was maintained at 10 to $12 \mathrm{~mL} \cdot \mathrm{kg}^{-1}$. $\min ^{-1}$ using an independent roller pump, and balloon tip pressure was maintained between 30 and $40 \mathrm{~mm} \mathrm{Hg}$. The distal aortic arch or the descending aorta was transected from inside the aorta to avoid injury to the recurrent nerve during circulatory arrest (CA) of the lower part of the body (Figure 1,D). A sealed quadrifurcated Dacron graft or Triplex vascular graft (Terumo Corporation, Tokyo, Japan) was used. The open distal aortic anastomosis was performed using a 4-0 polypropylene suture with external Teflon felt reinforcement (Figure 1,E). An elephant trunk installation technique into the descending aorta was used for patients with acute type A dissection. After completion of the distal anastomosis, the lower body circulation was reinstituted through a branch graft and the tympanic/rectal temperature was rewarmed to $33^{\circ} \mathrm{C}$ (Figure 1, F) and maintained at this level during the following procedures. Coincident with rewarming, antegrade SCP flow was gradually increased while maintaining the baseline values of $\mathrm{rSO}_{2}$. However, antegrade $\mathrm{SCP}$ flow was limited below $1200 \mathrm{~mL} / \mathrm{min}$ to prevent brain edema. The proximal anastomosis was then accomplished, followed by coronary reperfusion (Figure 1, $G$ ). Aortic arch vessels were reconstructed with a 5-0 polypropylene suture. If patients also had carotid artery or intracranial artery stenosis/occlusion, reconstruction was performed before rewarming. After 2006, fluid balance during $\mathrm{CPB}$ was strictly controlled and kept below $1000 \mathrm{~mL}$ by the extracorporeal ultrafiltration method (CAPIOX hemoconcentrator HC11, Terumo
Cardiovascular Systems, Division of Terumo Corporation, Tokyo, Japan). Other concurrent procedures are shown in Table 1.

\section{Definition of Neurologic Deficits}

"Permanent neurologic dysfunction" was defined as the presence of deficits that persisted at discharge and were caused by the intraoperative procedure. "Transient dysfunction" was defined as transient loss of orientation, slurred language, agitation, or poor response to commands. Neurologic dysfunction caused by preoperative brain malperfusion associated with acute type A dissection, deep shock status, and postoperative atrial fibrillation was excluded from this category.

\section{Statistical Analysis}

Data were processed using Stat View J-5.0 software (SAS Institute, Inc, Cary, NC). Continuous values are expressed as the mean \pm standard deviation. Data were analyzed by the $\chi^{2}$ test for categorical variables. Stepwise logistic regression analysis was performed to identify the risk factors for hospital mortality, permanent neurologic deficit (PND), and transient neurologic deficit (TND). Clinically relevant variables with $P<.05$ on univariate analysis were incorporated into the multivariate models. Survival and freedom from aorta-related death were assessed by the Kaplan-Meier method. Differences were considered statistically significant at $P<.05$.

\section{RESULTS}

Average CPB time, myocardial ischemic time, lower body CA time, SCP time, and minimum tympanic and rectal temperatures were $190.3 \pm 70.4$ minutes, $91.3 \pm 51.4$ minutes, $42.4 \pm 27.8$ minutes, $97.3 \pm 31.4$ minutes, $21.4^{\circ} \mathrm{C} \pm$ $1.7^{\circ} \mathrm{C}$, and $25.7^{\circ} \mathrm{C} \pm 2.3^{\circ} \mathrm{C}$, respectively. Fluid balance during CPB was $938.2 \pm 1541.7 \mathrm{~mL}$, but after 2006 the balance was strictly controlled below $1000 \mathrm{~mL}$ and values decreased significantly from $1311.0 \pm 1463.8 \mathrm{~mL}$ before 2006 to $712.5 \pm 1551.6 \mathrm{~mL}(P=.001)$ afterward.

Overall hospital mortality was $4.4 \%(14 / 320)$ and in elective cases, $1.9 \%$ (4/215). Figure 2 provides annual figures for number of cases and hospital mortality. The cause of death in all cases was as follows: central nervous system in 5 patients (4 with preoperative brain malperfusion and 1 with preoperative deep shock), sepsis in 3, gastrointestinal tract necrosis in 3 , pulmonary related in 2 , and hemorrhage in 1 . The cause of death in elective cases was gastrointestinal tract necrosis in 2 , sepsis in 1 , and pulmonary related in 1. Table 2 shows the univariate and multivariate analysis for in-hospital mortality. Multivariate analysis demonstrated that risk factors for hospital mortality were octogenarian (odds ratio $[\mathrm{OR}], 4.32 ; P=.03$ ), brain malperfusion (OR, $21.2 ; P=.001)$, and CPB time (OR, $1.01 ; P=.04)$.

A PND occurred in $14(4.4 \%)$ patients after surgery and in $6(2.8 \%)$ patients operated on electively. An additional 5 patients had a neurologic deficit preoperatively, caused by brain malperfusion in 4 and by deep shock status in 1, resulting from left main trunk malperfusion associated with acute type A aortic dissection. Two patients had stroke secondary to postoperative atrial fibrillation. Table 3 shows the univariate analysis for PND. Univariate analysis failed to identify a risk factor for PND. ATND occurred in $21(6.5 \%)$ patients after surgery and in $19(8.8 \%)$ patients operated on 
TABLE 1. Patient profiles

\begin{tabular}{|c|c|c|}
\hline Variables & No. & $\%$ \\
\hline No. of patients & 321 & \\
\hline Age $(y)$, mean \pm SD & $69.8 \pm 13.3$ & \\
\hline Octogenarian & 66 & 20.6 \\
\hline Male gender & 234 & 72.9 \\
\hline \multicolumn{3}{|l|}{ Aortic disease } \\
\hline Dissection & 94 & 28.3 \\
\hline Acute type A dissection & 61 & 19.0 \\
\hline Brain malperfusion & 8 & 2.5 \\
\hline Nondissection & 227 & 70.7 \\
\hline Shaggy aorta & 36 & 11.2 \\
\hline Marfan syndrome & 11 & 3.4 \\
\hline Emergency/urgent & 106 & 33.0 \\
\hline Rupture & 26 & 8.1 \\
\hline Shock & 9 & 2.8 \\
\hline Diabetes mellitus & 37 & 11.5 \\
\hline Old cerebral infarction & 32 & 10.0 \\
\hline Coronary artery disease & 72 & 22.4 \\
\hline Left ventricular EF $(\leq 40 \%)$ & 11 & 3.4 \\
\hline Chronic obstructive pulmonary disease & 23 & 7.2 \\
\hline Chronic kidney disease $(\mathrm{Cr} \geq 2.0)$ & 25 & 7.8 \\
\hline EuroSCORE & $8.2 \pm 2.6$ & \\
\hline Concurrent procedure & 122 & 38.0 \\
\hline Coronary artery bypass grafting & 72 & 22.4 \\
\hline Aortic root replacement (valve-sparing) & 12 & 3.7 \\
\hline Aortic root replacement (Bentall) & 4 & 1.2 \\
\hline Aortic valve replacement & 5 & 1.6 \\
\hline Mitral valve repair & 3 & 0.9 \\
\hline Maze procedure & 8 & 2.5 \\
\hline Abdominal aortic replacement & 4 & 1.2 \\
\hline \multicolumn{3}{|l|}{ Cannulation sites/type for CPB } \\
\hline Ascending aorta/arch & 244 & 76.0 \\
\hline Femoral artery & 54 & 16.8 \\
\hline Axillary artery & 3 & 0.9 \\
\hline Femoral artery + axillary artery & 8 & 2.5 \\
\hline Ascending aorta + femoral artery & 10 & 3.1 \\
\hline 24F Dispersion cannula & 138 & 43.0 \\
\hline
\end{tabular}

electively. Table 4 shows the univariate and multivariate analysis for TND. Multivariate analysis demonstrated that risk factors for TND were the aortic pathologic condition of shaggy aorta $(\mathrm{OR}, 3.73 ; P=.018)$ and low left ventricular ejection fraction $(\leq 40 \%)(\mathrm{OR}, 4.90 ; P=.05)$.

Additional postoperative complications are shown in Table 5. Mean mechanical ventilation time was $26.5 \pm$ 46.4 hours. As for respiratory complications, 53 (16.5\%) patients required prolonged mechanical ventilation $(\geq 48$ hours). The incidence was $22.8 \%$ before and $12.6 \%$ after 2006 with a significant difference $(P=.02)$.

Follow-up was completed in $94.1 \%$ of patients, and the mean follow-up period was $2.3 \pm 2.2$ years. Figure 3 shows overall long-term survival assessed by the Kaplan-Meier method. Survival at 3 and 5 years after surgery was $82.4 \% \pm 2.5 \%$ and $78.5 \% \pm 3.1 \%$, respectively.
Figure 4 shows freedom from aorta-related death assessed by the Kaplan-Meier method. There were 4 patients who died of aorta-related events during follow-up. Causes of death were rupture of the penetrating atherosclerotic ulcer in the descending aorta 1 year after TAR, rupture of thoracoabdominal aortic aneurysm 3 years after TAR, sudden death with hemoptysis, which presumably was caused by aortopulmonary fistula, and sudden death of unknown reason 4 months after TAR. The freedom from aorta-related death at 3 and 5 years after surgery was $97.9 \% \pm 1.1 \%$ and $97.9 \% \pm 1.1 \%$, respectively.

\section{DISCUSSION}

The major findings of this study were that a standardized approach for TAR since 2002 at our institute has resulted in a low hospital mortality and morbidity with a favorable longterm survival and freedom from aorta-related death. Details are spelled out in the "Current Surgical Approach" section.

The selection of an arterial cannulation site and type of cannula are important in preventing atheroembolic events, particularly neurologic complications. The efficacy of various kinds of arterial cannulation sites has been reported. Strauch, ${ }^{6}$ Ogino, ${ }^{2}$ and their associates reported that SCP with right axillary artery perfusion had a protective effect against stroke. When severe atherosclerotic changes are observed in the orifice of the brachiocephalic artery or on the posterior wall of the ascending aorta, ${ }^{7}$ perfusion through the axillary artery should be performed with caution. In most instances, we selected the ascending aorta as an arterial cannulation site after inspection of the epiaortic echographic scan. Grooters and colleagues ${ }^{8}$ described the advantages of arterial perfusion toward the aortic valve. In an experimental study, Fukuda and coworkers ${ }^{9}$ confirmed that directing the cannula tip of the Dispersion cannula toward the aortic root generated slower and less turbulent flow in the transverse arch of the glass models of both healthy and aneurysmal aortic arches. We often experienced that the atherosclerotic change was less frequent just distal to the sinotubular junction. Accordingly, when we noted the presence of severe atheroma in the ascending aorta/aortic arch, we selected the 24F Dispersion cannula and inserted it into the ascending aorta near the aortic root with perfusion toward the aortic valve. That was a major reason that we seldom selected the right axillary artery perfusion. We could completely avoid PND in patients with shaggy aorta by this approach. We believe the approach may have contributed to the low incidence of neurologic complications that we observed (PND, 4.4\%; TND, 6.6\%), although univariate and multivariate analysis failed to identify the use of a Dispersion cannula as one of the risk reduction factors for PND or TND. In patients with acute type A dissection, a femoral artery cannulation was mainly applied. Inasmuch as the approach is one of the main providers of malperfusion syndrome, we have recently applied an ascending aortic 
A
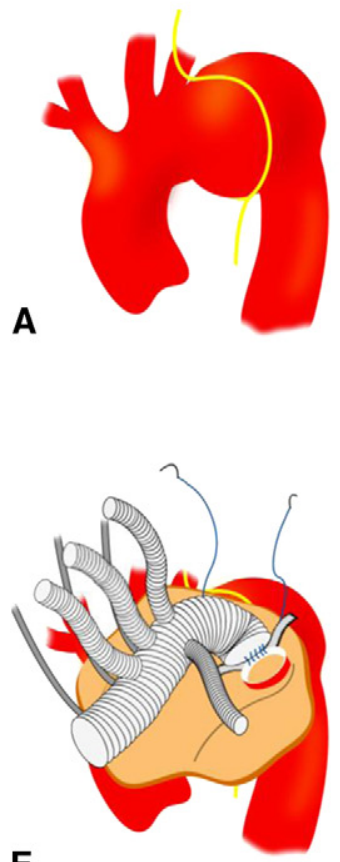

E
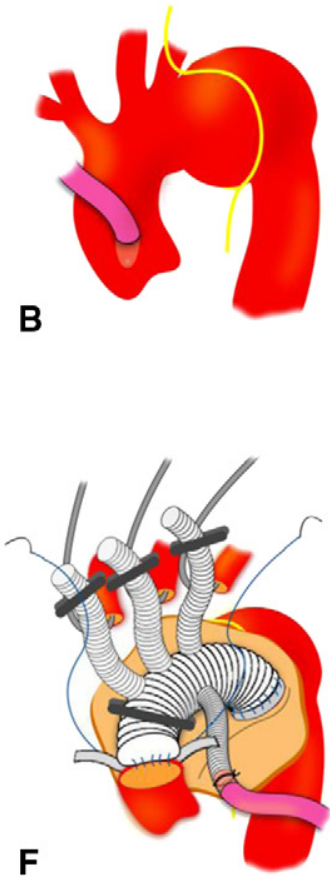

B
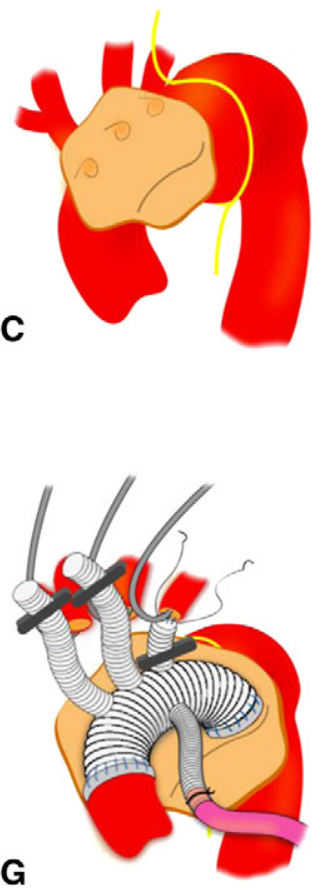

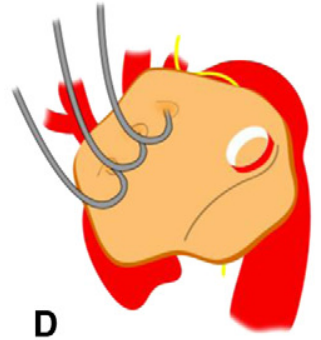

D

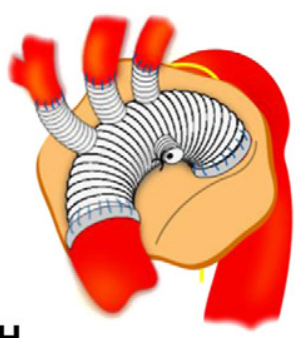

H

FIGURE 1. Surgical procedure. A, Aortic arch exposure. B, Aortic cannulation. C, Aortic arch is opened under circulatory arrest at $20^{\circ} \mathrm{C}$ to $23^{\circ} \mathrm{C}($ tympanic temperature). D, Antegrade selective cerebral perfusion from inside the aortic arch with trimming of the descending aorta. E, Distal anastomosis under circulatory arrest of the lower part of the body. F, Lower body reperfusion through the branch graft and early rewarming while monitoring of near-infrared spectroscopy, followed by proximal anastomosis. G, Coronary reperfusion and arch vessel reconstruction, preceded by repair without rewarming of stenosis/occlusion lesions of carotid or intracranial arteries. H, Discontinuation of cardiopulmonary bypass and completion of total arch replacement.

cannulation ${ }^{10}$ using a Seldinger method. That was another reason for scarcity of the right axillary artery perfusion.

Some risk factors for stroke in connection with aortic surgery have been identified.

Aortic diseasse has not been included in the preoperative risk stratification system such as EuroSCORE but is apparently one of the risk factors for adverse neurologic outcomes. Our group previously reported that severity of the aortic arch atheroma grades has been identified as another risk factor for adverse neurologic outcomes. ${ }^{11}$ Shaggy aorta

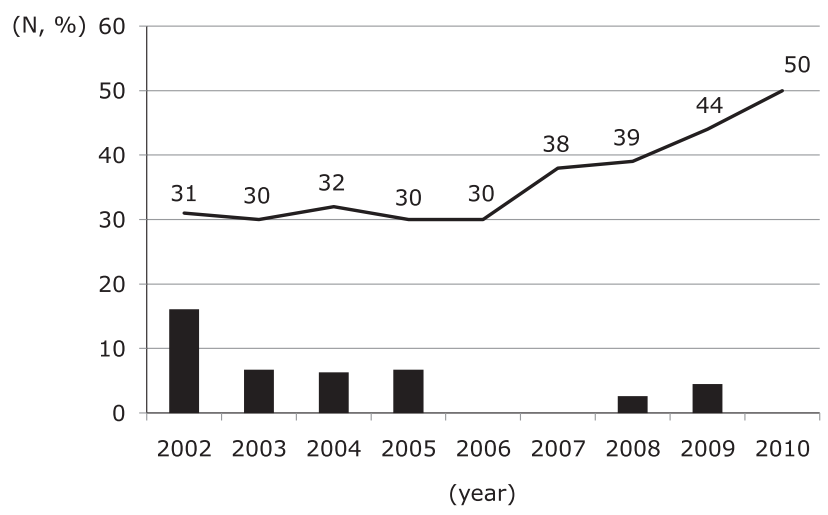

FIGURE 2. Number of cases and hospital mortality. Solid line depicts the number of cases of total arch replacement and bar graphs the overall hospital mortality. has extensive friable and soft atheromatous lesions. ${ }^{4}$ Amarenco and colleagues ${ }^{12}$ indicated a strong, independent association between atherosclerotic disease of the aortic arch and the risk of ischemic stroke, particularly with thick plaque $(\geq 4 \mathrm{~mm})$. There were 36 patients with shaggy aorta in this study. None of 36 patients had PND and $10(27.8 \%)$ of 36 patients had TND. Multivariate analysis demonstrated that shaggy aorta was a risk factor for TND but not for PND. We believe that meticulous selection of cannulation site and type of cannula based on the preoperative and intraoperative accurate imaging for aortic disease and complete exclusion of the diseased aorta contributed to avoid PND even in cases of shaggy aorta.

Contemporary strategies for brain protection are deep hypothermic arrest with or without retrograde cerebral perfusion ${ }^{13}$ or SCP. ${ }^{14}$ Although deep hypothermic arrest with or without retrograde cerebral perfusion does not require an additional circuit for the brain perfusion, the safety margin is limited to 40 to 60 minutes. $^{3,15}$ A prospective comparative study by one of the coauthors ${ }^{16}$ confirmed that SCP significantly reduced the prevalence of temporary neurologic dysfunction compared with retrograde cerebral perfusion. Since then, we have consistently selected SCP under deep hypothermia for brain protection.

The temperature of hypothermic CA during the distal anastomosis is particularly crucial for protecting vital 
TABLE 2. Risk factors for hospital mortality identified by univariate and multivariate analysis

\begin{tabular}{|c|c|c|c|c|}
\hline \multirow[b]{2}{*}{ Variables } & \multicolumn{2}{|l|}{ Univariate } & \multicolumn{2}{|l|}{ Multivariate } \\
\hline & OR $(95 \%$ CI $)$ & $\begin{array}{c}P \\
\text { value }\end{array}$ & OR $(95 \%$ CI $)$ & $\begin{array}{c}P \\
\text { value }\end{array}$ \\
\hline Octogenarian & 3.09 (1.03-9.23) & .04 & $4.32(1.19-15.7)$ & .03 \\
\hline Male gender & $0.65(0.21-2.02)$ & .46 & & \\
\hline Dissection & $1.87(0.63-5.54)$ & .26 & & \\
\hline Brain malperfusion & $30.3(6.61-138.9)$ & $<.0001$ & $21.2(3.47-130.1)$ & .001 \\
\hline Shaggy aorta & $1.34(0.29-6.24)$ & .71 & & \\
\hline Emergency/urgent & $5.50(1.68-18.0)$ & .005 & $2.31(0.56-9.55)$ & .25 \\
\hline Rupture & $1.97(0.42-9.30)$ & .39 & & \\
\hline Shock & $2.88(0.33-24.7)$ & .34 & & \\
\hline Diabetes mellitus & $0.58(0.07-4.56)$ & .60 & & \\
\hline $\begin{array}{l}\text { Old cerebral } \\
\text { infarction }\end{array}$ & $2.61(0.69-9.91)$ & .16 & & \\
\hline $\begin{array}{l}\text { Coronary artery } \\
\text { disease }\end{array}$ & $2.74(0.92-8.17)$ & .07 & & \\
\hline $\begin{array}{l}\text { Low LVEF } \\
(\leq 40 \%)\end{array}$ & $2.29(0.27-19.2)$ & .44 & & \\
\hline COPD & $2.27(0.48-10.8)$ & .30 & & \\
\hline CKD & $2.06(0.43-9.76)$ & .36 & & \\
\hline $\begin{array}{l}\text { Concurrent } \\
\text { procedure }\end{array}$ & $1.23(0.42-3.63)$ & .71 & & \\
\hline CPB time & $1.01(1.00-1.01)$ & .006 & $1.01(1.00-1.01)$ & .04 \\
\hline $\begin{array}{l}\text { Tympanic } \\
\text { temperature }\end{array}$ & $0.81(0.57-1.14)$ & .81 & & \\
\hline $\begin{array}{l}\text { Fluid balance } \\
\text { during CPB } \\
\end{array}$ & $1.0(1.0-1.0)$ & .95 & & \\
\hline
\end{tabular}

organs. Inasmuch as the primary goal of core cooling is to achieve a brain temperature compatible with the maximum suppression of metabolism, the lowest temperature that can be safely achieved is optimal for brain protection. On the other hand, deep hypothermia tends to be associated with coagulopathy, which is to be avoided. Apart from the deep hypothermic CA with or without retrograde cerebral perfusion, the optimal temperature in the setting of antegrade SCP seems to be between $20^{\circ} \mathrm{C}$ and $28^{\circ} \mathrm{C}^{1,17,18}$ Minatoya and associates ${ }^{18}$ reported that the temperature during hypothermic CA could be safely increased to $28^{\circ} \mathrm{C}$ with a high SCP flow rate and that the incidence of neurologic events was not increased with significant reduction of CA and SCP time. Inasmuch as we have focused more on the issue of organ protection, we set tympanic temperature between $20^{\circ} \mathrm{C}$ and $23^{\circ} \mathrm{C}$, resulting in optimal CA and SCP times $(42.4 \pm 27.8$ and $97.3 \pm 31.4$ minutes, respectively). As for the rectal temperature, we aimed it below $30^{\circ} \mathrm{C}$ just before CA. One of our patients whose rectal temperature before CA was in excess of $30^{\circ} \mathrm{C}$ had entire colon necrosis, presumably because of calcified stenosis of the mesenteric artery with poor visceral circulation.
TABLE 3. Risk factors for PND identified by univariate analysis

\begin{tabular}{lcc}
\hline \multirow{2}{*}{ Variables } & \multicolumn{2}{c}{ Univariate } \\
\cline { 2 - 3 } Octogenarian & OR $(\mathbf{9 5} \%$ CI) & $\boldsymbol{P}$ value \\
Male gender & $1.06(0.29-3.90)$ & .93 \\
Dissection & $1.38(0.38-5.07)$ & .63 \\
Emergency/urgent & $1.87(0.63-5.53)$ & .16 \\
Rupture & $2.84(0.96-8.42)$ & .06 \\
Shock & $3.37(0.88-12.9)$ & .08 \\
Diabetes mellitus & $2.99(0.34-26.4)$ & .32 \\
Old cerebral infarction & $0.58(0.07-4.56)$ & .58 \\
Coronary artery disease & $1.54(0.33-7.21)$ & .58 \\
CKD & $1.41(0.43-4.62)$ & .57 \\
Concurrent procedure & $2.06(0.43-9.76)$ & .36 \\
CPB time & $1.23(0.42-3.63)$ & .71 \\
SCP time & $1.004(1.00-1.01)$ & .25 \\
Tympanic temperature & $1.01(1.00-1.02)$ & .11 \\
Fluid balance during CPB & $1.06(0.79-1.42)$ & .70 \\
Use of 24F Dispersion cannula & $1.0(1.0-1.0)$ & .14 \\
Variables of shaggy aorta, shock status, low left ventricular ejection fraction, and COPD \\
were not tested because PND did not occur in cases with the factors. $P N D$, Permanent \\
neurologic deficit; $O R$, odds ratio; $C I$, confidence interval; $C K D$, chronic kidney disease \\
(creatinine $\geq 2.0) ; C P B$, cardiopulmonary bypass; $S C P$, selective cerebral perfusion.
\end{tabular}

Subsequently, we have always kept rectal temperatures below $30^{\circ} \mathrm{C}$, without further such complications.

To minimize CPB time, we start rewarming as soon as the distal anastomosis is completed, with concurrent antegrade distal reperfusion to the lower part of the body through the prosthetic graft branch. Monitoring brain oxygenation during rewarming is particularly important because the brain becomes metabolically hyperactive with progressive oxygen desaturation as a result of the uncoupling of the linear relationship between brain blood flow and temperature. NIRS has been used to monitor $\mathrm{rSO}_{2}$ in several clinical settings. Olsson and Thelin ${ }^{19}$ reported the efficacy on NIRS as a noninvasive cerebral saturation trend monitor in antegrade SCP. Baseline values are highly variable between patients, with mean stable $\mathrm{rSO}_{2}$ levels ranging from $45 \%$ to $90 \%$, making it essential to follow trends in oxygen saturation changes rather than absolute values. We increased SCP flow from 10 to $15 \mathrm{~mL} \cdot \mathrm{min}^{-1} \cdot \mathrm{m}^{-2}$ to maintain preoperative values of NIRS; however, the total flow was always maintained below $1200 \mathrm{~mL} / \mathrm{min}$ to avoid brain edema.

The use of CPB is invariably associated with fluid overload followed by fluid extravasation from the circulation to the interstitial space, which occasionally leads to organ dysfunction, particularly in the lungs. The main causes of CPB-related edema are the occurrence of systemic inflammatory responses and hemodilution. Strategies to reduce the inflammatory response have chiefly focused on the pharmacologic approaches. Steroids are often used as antiinflammatory agents and may lessen complement activation by causing in vitro inhibition of C 3 and C5 convertase. ${ }^{20}$ However, there are few reports that demonstrate clinically 
TABLE 4. Risk factors for TND identified by univariate and multivariate analysis

\begin{tabular}{|c|c|c|c|c|}
\hline \multirow[b]{2}{*}{ Variables } & \multicolumn{2}{|c|}{ Univariate } & \multicolumn{2}{|c|}{ Multivariate } \\
\hline & OR $(95 \%$ CI $)$ & $\begin{array}{c}P \\
\text { value }\end{array}$ & OR $(95 \%$ CI $)$ & $\begin{array}{c}P \\
\text { value }\end{array}$ \\
\hline Octogenarian & $1.22(0.43-3.47)$ & .70 & & \\
\hline Male gender & $2.33(0.67-8.12)$ & .18 & & \\
\hline Dissection & $0.11(0.02-0.84)$ & .04 & $0.48(0.05-5.00)$ & .54 \\
\hline Shaggy aorta & $9.58(3.72-24.7)$ & $<.0001$ & $3.73(1.26-11.1)$ & .018 \\
\hline Emergency/urgent & $0.20(0.05-0.87)$ & .04 & $0.73(0.13-4.09)$ & .72 \\
\hline Rupture & $0.55(0.07-4.27)$ & .57 & & \\
\hline Diabetes mellitus & $0.80(0.18-3.57)$ & .77 & & \\
\hline $\begin{array}{l}\text { Old cerebral } \\
\text { infarction }\end{array}$ & $1.56(0.43-5.61)$ & .50 & & \\
\hline $\begin{array}{l}\text { Coronary artery } \\
\text { disease }\end{array}$ & $4.31(1.75-10.6)$ & .002 & $2.36(0.45-12.3)$ & .31 \\
\hline Low LVEF $(\leq 40 \%)$ & $9.85(2.63-37.0)$ & .0007 & $4.90(1.00-23.9)$ & .05 \\
\hline COPD & $4.90(1.61-14.9)$ & .05 & $2.04(0.54-7.75)$ & .30 \\
\hline CKD & $3.13(0.96-10.1)$ & .05 & & \\
\hline $\begin{array}{l}\text { Concurrent } \\
\text { procedure }\end{array}$ & $2.83(1.14-7.05)$ & .03 & $0.80(0.15-4.20)$ & .79 \\
\hline CPB time & $1.00(1.00-1.01)$ & .27 & & \\
\hline SCP time & $0.99(0.98-1.01)$ & .45 & & \\
\hline $\begin{array}{l}\text { Tympanic } \\
\text { temperature }\end{array}$ & $0.89(0.68-1.16)$ & .77 & & \\
\hline $\begin{array}{l}\text { Use of } 24 \mathrm{~F} \\
\text { Dispersion } \\
\text { cannula } \\
\end{array}$ & $6.29(0.24-2.22)$ & .001 & $2.49(0.71-8.76)$ & .16 \\
\hline $\begin{array}{l}\text { A variable of shock status } \\
\text { occur in cases associatec } \\
\text { ratio; } C I \text {, confidence inte } \\
\text { obstructive pulmonary di } \\
\text { cardiopulmonary bypass }\end{array}$ & $\begin{array}{l}\text { was not tested becal } \\
\text { with shock. } T N D \text {, } \\
\text { rval; } L V E F \text {, left vent } \\
\text { sease; } C K D \text {, chronic } \\
S C P \text {, selective cerel }\end{array}$ & se perman & $\begin{array}{l}\text { ent neurologic deficit } \\
\text { neurologic deficit; } O \\
\text { ction fraction; } C P D \text {, } \\
\text { ease (creatinine } \geq 2.0 \\
\text { ion. }\end{array}$ & $\begin{array}{l}\text { did not } \\
R \text {, odds } \\
\text { chronic } \\
\text { ); } C P B \text {, }\end{array}$ \\
\hline
\end{tabular}

significant in vivo effects of these agents. ${ }^{21}$ Neutrophil activation and sequestration, by facilitating secretion of neutrophil elastase, may also cause pulmonary dysfunction. Sivelestat sodium hydrate is a synthetic low-molecularweight specific neutrophil elastase inhibitor. ${ }^{22}$ We have used $100 \mathrm{mg}$ of sivelestat into the pump circuit at the

TABLE 5. Additional postoperative complications

\begin{tabular}{lc}
\hline \multicolumn{1}{c}{ Variables } & No $(\%)$ \\
\hline Paraplegia & $3(0.9)$ \\
Temporary & $1(0.3)$ \\
Permanent & $2(0.6)$ \\
Paraparesis & $1(0.3)$ \\
Temporary & $1(0.3)$ \\
Mediastinitis & $7(2.4)$ \\
Mean mechanical ventilation time $(\mathrm{h})$ & $26.5 \pm 46.4$ \\
Prolonged ventilation $(\geq 48 \mathrm{~h})$ & $53(16.5)$ \\
Prolonged ventilation after 2006 & $25(12.6)^{*}$ \\
Renal failure & $10(3.1)$ \\
Gastrointestinal tract & $8(2.5)$ \\
Bleeding & $6(1.9)$ \\
Necrosis & $2(0.6)$ \\
\hline
\end{tabular}

$* P=.02$ versus before 2006

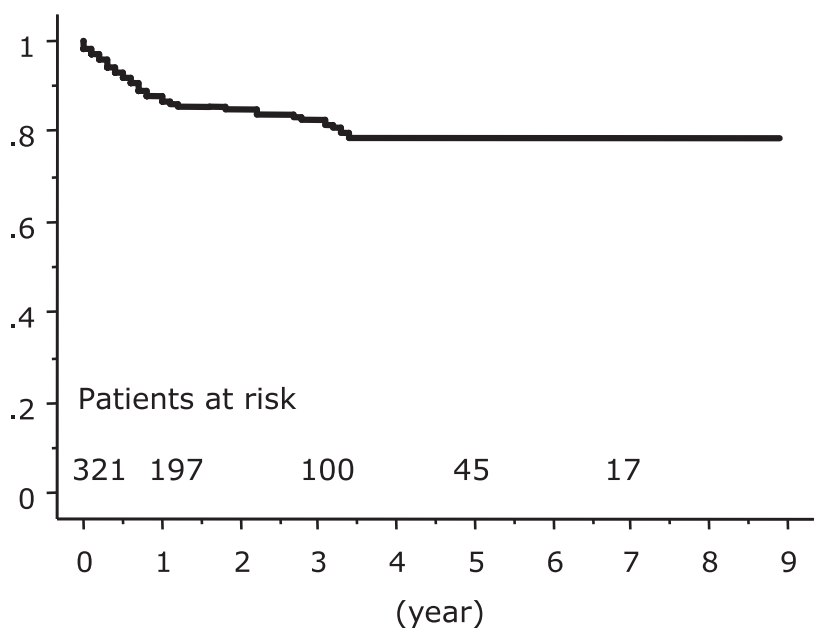

FIGURE 3. Survival curve. Survival at 3 and 5 years after surgery was $82.4 \% \pm 2.5 \%$ and $78.5 \% \pm 3.1 \%$, respectively.

initiation of $\mathrm{CPB}$ with attenuation of postoperative pulmonary dysfunction as assessed from respiratory and oxygenation indices, and with earlier tracheal extubation. ${ }^{5}$ As regards hemodilution, a highly positive fluid balance during CPB is associated with adverse outcomes such as increases in the requirement for blood transfusion and in-hospital mortality. ${ }^{23}$ Inasmuch as lungs are particularly susceptible to fluid overload, pulmonary dysfunction may occur and result in prolonged postoperative mechanical ventilatory support. ${ }^{24}$ Therefore, maintaining fluid balance as close to physiologic as possible is crucial. Oliver and associates ${ }^{25}$ reported that control of fluid balance by hemofiltration facilitated earlier tracheal extubation after normothermic $\mathrm{CPB}$, although no mechanism was elucidated to account for this result. The literature reported that hemofiltration during CPB resulted in $27 \mathrm{~mL} / \mathrm{kg}^{26}$ of ultrafiltrate with $1.18 \pm 1.99 \mathrm{~L}$ of fluid balance. Beginning in 2006, we

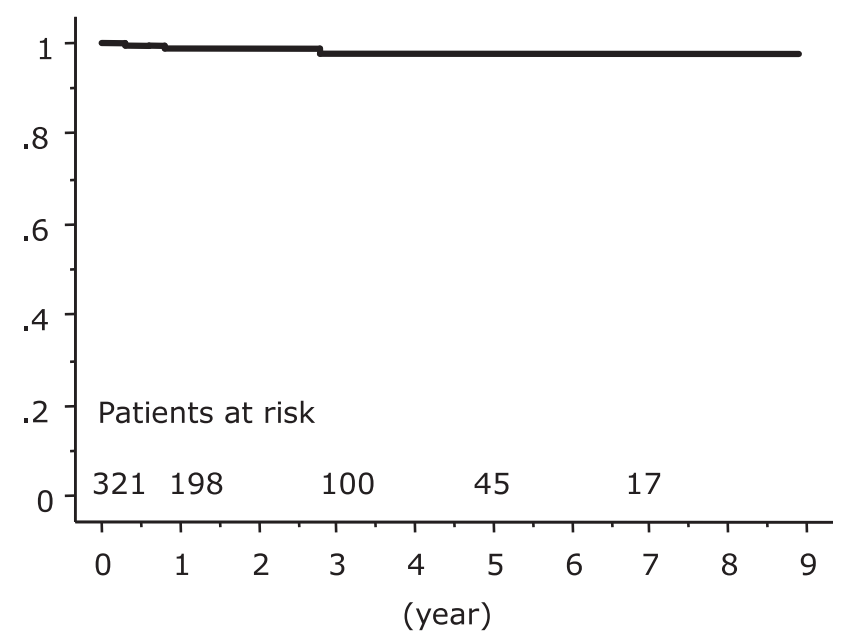

FIGURE 4. Freedom from aorta-related death. Freedom from aortarelated death 3 and 5 years after surgery was $97.9 \% \pm 1.1 \%$ and $97.9 \% \pm 1.1 \%$, respectively. 
also sought to achieve a 1-L fluid balance and noted a significant decrease from $1311.0 \pm 1463.8 \mathrm{~mL}$ before 2006 to $712.5 \pm 1551.6 \mathrm{~mL}(P=.001)$ afterward, as well a reduction in the percentage of patients requiring prolonged ventilation from $22.8 \%$ to $12.6 \%(P=.02)$. Inasmuch as optimal fluid balance during CPB under deep hypothermia remains unknown, further investigation of this issue will be required.

Previous reports have demonstrated improved outcomes both in mortality and in the incidence of permanent stroke resulting from various kinds of multimodal approaches. ${ }^{1,2,17,27}$ Recent reports have indicated that results of conventional aortic arch surgery even in octogenarians is improving. ${ }^{28}$ In the current study, overall hospital mortality was satisfactory but that in octogenarian was $9.1 \%(6 / 66)$ and the status was identified as a risk factor for hospital mortality (OR, $4.32 ; P=.03)$. However, our evolving procedures provided the drastic improvement in octogenarians with a significant reduction in hospital mortality over the 5 years $(14.2 \%$ before 2006 vs $2.6 \%$ after $2006, P=.03$ ). We can expect further advancements in the era of the aged society. Although the underlying specific reasons for the recent improvement in outcomes from use of standardized approaches remain unclear, there is evidence at our institute that strict water balance during CPB may be one of the important factors.

Finally, the long-term outcome was satisfactory, particularly in the freedom from aorta-related death, which confirmed that TAR was evolving treatment with better durability.

\section{LIMITATIONS}

This is a retrospective study from a single center. Although the favorable outcomes we observed appeared to be the result of our standardized surgical approach for TAR, further prospective studies are required to validate this process and identify those factors that contribute most strongly to this outcome.

\section{CONCLUSIONS}

Our approach for TAR has contributed to low hospital mortality and morbidities and with favorable long-term outcome.

\section{References}

1. Kazui T, Yamashita K, Washiyama N, Terada H, Bashar AH, Suzuki K, et al. Aortic arch replacement using selective cerebral perfusion. Ann Thorac Surg. 2007;83:S796-8.

2. Ogino H, Sasaki H, Minatoya K, Matsuda H, Tanaka H, Watanuki H, et al. Evolving arch surgery using integrated antegrade selective cerebral perfusion: impact of axillary artery perfusion. J Thorac Cardiovasc Surg. 2008;136:641-8.

3. Svensson LG, Crawford ES, Hess KR, Coselli JS, Raskin S, Shenaq SA, et al. Deep hypothermia with circulatory arrest: determinants of stroke and early mortality in 656 patients. J Thorac Cardiovasc Surg. 1993;106:19-28.

4. Hollier LH, Kazmier FJ, Ochsner J, Bowen JC, Procter CD. "Shaggy" aorta syndrome with atheromatous embolization to visceral vessels. Ann Vasc Surg. 1991; 5:439-44.

5. Morimoto N, Morimoto K, Morimoto Y, Takahashi H, Asano M, Matsumori M, et al. Sivelestat attenuates postoperative pulmonary dysfunction after total arch replacement under deep hypothermia. Eur J Cardiothorac Surg. 2008;34:798-804.
6. Strauch JT, Spielvogel D, Lauten A, Lansman SL, McMurtry K, Bodian CA, et al. Axillary artery cannulation: routine use in ascending aorta and aortic arch replacement. Ann Thorac Surg. 2004;78:103-8.

7. Minakawa M, Fukuda I, Inamura T, Yanaoka H, Fukui K, Daitoku K, et al. Hydrodynamic evaluation of axillary artery perfusion for normal and diseased aorta. Gen Thorac Cardiovasc Surg. 2008;56:215-21.

8. Grooters RK, Thieman KC, Schneider RF, Nelson MG. Assessment of perfusion toward the aortic valve using the new dispersion aortic cannula during coronary artery bypass surgery. Tex Heart Inst J. 2000;27:361-5.

9. Fukuda I, Fujimori S, Daitoku K, Yanaoka H, Inamura T. Flow velocity and turbulence in the transverse aorta of a proximally directed aortic cannula: hydrodynamic study in a transparent model. Ann Thorac Surg. 2009;87:1866-71.

10. Minatoya K, Karck M, Szpakowski E, Harringer W, Haverich A. Ascending aortic cannulation for Stanford type A acute aortic dissection: another option. $J$ Thorac Cardiovasc Surg. 2003;125:952-3.

11. Morimoto N, Okada K, Uotani K, Kanda F, Okita Y. Leukoaraiosis and hippocampal atrophy predict neurologic outcome in patients who undergo total aortic arch replacement. Ann Thorac Surg. 2009;88:476-81.

12. Amarenco P, Cohen A, Tzourio C, Bertrand B, Hommel M, Besson G, et al. Ath erosclerotic disease of the aortic arch and the risk of ischemic stroke. $N$ Engl J Med. 1994;331:1474-9.

13. Ueda Y, Miki S, Kusuhara K, Okita Y, Tahata T, Yamanaka K. Surgical treatment of aneurysm or dissection involving the ascending aorta and aortic arch, utilizing circulatory arrest and retrograde cerebral perfusion. J Cardiovasc Surg (Torino). 1990;31:553-8.

14. Kazui T, Washiyama N, Muhammad BA, Terada H, Yamashita K, Takinami M. Improved results of atherosclerotic arch aneurysm operations with a refined technique. J Thorac Cardiovasc Surg. 2001;121:491-9.

15. Ueda $Y$. What is the best method for brain protection in surgery of the aortic arch? Retrograde cerebral perfusion. Cardiol Clin. 2010;28:371-9.

16. Okita Y, Minatoya K, Tagusari O, Ando M, Nagatsuka K, Kitamura S. Prospective comparative study of brain protection in total aortic arch replacement: deep hypothermic circulatory arrest with retrograde cerebral perfusion or selective antegrade cerebral perfusion. Ann Thorac Surg. 2001;72:72-9.

17. Bachet J, Guilmet D, Goudot B, Dreyfus GD, Delentdecker P, Brodaty D, et al. Antegrade cerebral perfusion with cold blood: a 13-year experience. Ann Thorac Surg. 1999;67:1874-8.

18. Minatoya K, Ogino H, Matsuda H, Sasaki H, Tanaka H, Kobayashi J, et al. Evolving selective cerebral perfusion for aortic arch replacement: high flow rate with moderate hypothermic circulatory arrest. Ann Thorac Surg. 2008;86:1827-31.

19. Olsson C, Thelin S. Regional cerebral saturation monitoring with near-infrared spectroscopy during selective antegrade cerebral perfusion: diagnostic performance and relationship to postoperative stroke. J Thorac Cardiovasc Surg. 2006;131:371-9.

20. Moat NE, Shore DF, Evans TW. Organ dysfunction and cardiopulmonary bypass: the role of complement and complement regulatory proteins. Eur J Cardiothorac Surg. 1993; 7:563-73.

21. Sobieski MA, Graham JD, Pappas PS, Tatooles AJ, Slaughter MS. Reducing the effects of the systemic inflammatory response to cardiopulmonary bypass: can single dose steroids blunt systemic inflammatory response syndrome? ASAIO J. 2008;54:203-6.

22. Yamazaki T, Ooshima H, Usui A, Watanabe T, Yasuura K. Protective effects of ONO-5046*Na, a specific neutrophil elastase inhibitor, on postperfusion lung injury. Ann Thorac Surg. 1999;68:2141-6.

23. Toraman F, Evrenkaya S, Yuce M, Turek O, Aksoy N, Karabulut H, et al. Highly positive intraoperative fluid balance during cardiac surgery is associated with adverse outcome. Perfusion. 2004;19:85-91.

24. Asimakopoulos G, Smith PL, Ratnatunga CP, Taylor KM. Lung injury and acute respiratory distress syndrome after cardiopulmonary bypass. Ann Thorac Surg. 1999;68:1107-15.

25. Oliver WC Jr, Nuttall GA, Orszulak TA, Bamlet WR, Abel MD, Ereth MH, et al. Hemofiltration but not steroids results in earlier tracheal extubation following cardiopulmonary bypass: a prospective, randomized double-blind trial. Anesthesiology. 2004;101:327-39.

26. Andreasson S, Gothberg S, Berggren H, Bengtsson A, Eriksson E, Risberg B. Hemofiltration modifies complement activation after extracorporeal circulation in infants. Ann Thorac Surg. 1993;56:1515-7.

27. Svensson LG, Nadolny EM, Kimmel WA. Multimodal protocol influence on stroke and neurocognitive deficit prevention after ascending/arch aortic operations. Ann Thorac Surg. 2002;74:2040-6.

28. Minatoya K, Ogino H, Matsuda H, Sasaki H, Tanaka H, Kobayashi J, et al. Is conventional aortic arch surgery justifiable in octogenarians? J Thorac Cardiovasc Surg. 2010;139:641-5. 